\title{
Evaluation of Passive Smoking by Measuring Urinary Trans, trans-muconic Acid and Exhaled Carbon Monoxide Levels
}

\author{
Shiho TANIGUCHI ${ }^{1 *}$, Masato NIITSUYA ${ }^{1}$, Yoko INOUE ${ }^{1}$, Hiroshi KATAGIRI ${ }^{2}$, \\ Takehiro KADOWAKI ${ }^{2}$ and Yoshiharu AIZAWA ${ }^{1}$
}

\author{
${ }^{1}$ Department of Preventive Medicine and Public Health, Kitasato University School of Medicine, 1-15-1, Kitasato, \\ Sagamihara, Kanagawa 228-8555, Japan \\ ${ }^{2}$ Kitasato University School of Allied Health Sciences, 1-15-1, Kitasato, Sagamihara, Kanagawa 228-8555, Japan
}

Received October 26, 1998 and accepted November 27, 1998

\begin{abstract}
No method has yet been established to evaluate the exposure to tobacco smoke in passive smoking (PS). We therefore conducted a study on the possibility that the levels of urinary trans, trans-muconic acid (MA) and the exhaled carbon monoxide (CO) could be indices of the passive exposure to tobacco smoke. The moderate correlation was observed between urinary MA levels and the number of consumed cigarettes per day in smokers. The mean urinary MA level of the PS (+) group was significantly higher than that with the PS (-) group. Among the PS (+) group, the mean MA level in the urine obtained in the afternoon was higher than that obtained in the morning. A high correlation was observed between the exhaled $\mathrm{CO}$ levels and the number of consumed cigarettes per day in smokers. Like the urinary MA level, the mean exhaled CO level in the PS (+) group, too, gave a significantly higher level than in the PS (-) group. Because the biological half life of MA (7.5 $\pm 0.85 \mathrm{~h})$ was longer than that of $\mathrm{CO}(3.0 \pm 0.36 \mathrm{~h})$, the measurement of urinary MA level is recommended for evaluating the exposure of passive smoking. The measurement of exhaled CO levels is useful only for chain smokers and nonsmokers with PS just before measurement.
\end{abstract}

Key words: Trans, Trans-muconic acid, Passive smoking, Environmental tobacco smoke, CO concentration in expirium, Benzene

\section{Introduction}

The health risks of smoking and passive smoking (PS) have become clear in recent years, and control for smoking is now an important issue that must be solved in the management of occupational health ${ }^{1-8)}$. In 1996, the Japanese Ministry of Labor issued the "Guideline on the partition of workplaces between smokers and nonsmokers".

At present, there is no established method of evaluating passive smoking. As indices for the exposure to tobacco smoke, attempts have been made until now to measure the

*To whom all correspondence should be addressed. levels of urinary cotinine, urinary trans, trans-muconic acid (MA) and of carbon monoxide (CO) in the expirium ${ }^{6,8,9-20)}$.

The urinary MA is one of the metabolites of benzene. The measurement of MA has been reported to be useful as a biological index for the exposure to trace amounts of benzene $^{21-24)}$. A small fraction of the urinary MA may be originated from the metabolism of sorbic acid, a customary additive in food, cosmetics and pharmaceutical products ${ }^{19}$. However, the amount of MA generated by the metabolism of ingested sorbic acid does not seem to be so significant as to discard MA as a benzene marker ${ }^{19}$. The cigarette smoke is known to emit benzene by pyrolysis of tobacco leaf ${ }^{15}$.

While exhaled $\mathrm{CO}$ levels are influenced by other sources 
of $\mathrm{CO}$ such as cooking, heating or vehicle exhaust, the measurement is very simple and convenient ${ }^{(6)}$.

We therefore studied the possibility of evaluating the exposure to tobacco smoke especially in passive smoking by measuring the urinary MA level and the $\mathrm{CO}$ concentration in the expirium of workers having no chance of exposure to benzene or combustion in their work.

\section{Subjects}

Six students and personnels of the university were the subjects for the time course studies of MA and CO levels after smoking.

The subjects of the PS study were a total of 285 persons who were employees of a company and the university personnels. Among them, there were 47 persons who were nonsmokers and had no passive smoking (PS [-] group), 103 persons who were nonsmokers but had passive smoking (PS [+] group), and 135 smokers.

As shown in Table 1, the subjects included 243 males and 42 females, with their average age and standard deviation being $37.3 \pm 11.1$ for males and $27.5 \pm 9.3$ for females $(\mathrm{P}<0.001)$. In nonsmokers, the average age of men was significantly higher than that of women $(\mathrm{P}<0.001)$. In nonsmokers, the mean age of PS (+) group was higher than PS $(-)$ group $(\mathrm{P}<0.001)$. The number of cigarettes consumed per day ranged 1-50 with an average of $22.1 \pm 11.3$.

Because the number of women was markedly smaller than that of men and sex difference of MA and CO data was negligible, the subjects for the following analysis were a total of men and women.

\section{Methods}

\section{Measurement of urinary MA level}

Urine samples were stored frozen at $20^{\circ} \mathrm{C}$. On the day of measurement, the samples were thawed at room temperature before use.

The measurement of MA was performed by a modified method of Ghittori et al. ${ }^{18)}$. High performance liquid chromatography (HPLC) was used for the measurement. One $\mathrm{ml}$ of urine sample was mixed with $1 \mathrm{ml}$ of citrate buffer (pH 5). After it was passed through a $0.2 \mu \mathrm{m}$ filter (GL Chromatodisk, Kurabo, Japan), one $\mathrm{ml}$ of the sample was treated with $3 \mathrm{ml}$ of an anionic exchange cartridge (Bond Elut SAX, Valian Associate, USA). The cartridge was conditioned with $3 \mathrm{ml}$ of methanol and $3 \mathrm{ml}$ of distilled water before use. After the cartridge was washed with $6 \mathrm{ml}$ of distilled water and $10 \mathrm{ml}$ of 0.5 percent acetic acid, MA was eluted with $4 \mathrm{ml}$ of 6 percent acetic acid.

The Hitachi L-400 UV Detector and Hitachi L-6300 Intelligent Pump (Hitachi, Ltd., Japan) were used for HPLC. The urinary MA level was expressed in $\mu \mathrm{g} / \mathrm{g} \cdot$ creatinine for adjusting creatinine of urine. The urinary creatinine was measured by the alkaline picric acid method.

\section{Time course of excretion of MA in the urine after smoking}

The smokers were asked to smoke 2 cigarettes (Seven Stars Light, Japan Tobacco Industry) in 10 minutes with the informed consent. Urinary MA levels were measured before smoking and 1, 2, 3, 4, 5, 6, 7, 8 and 10 hours after smoking. They were asked not to smoke other than for the experiments on the test day from the time of waking up to the last urine sampling.

Table 1. The average age of the subjects according to sex and smoking

\begin{tabular}{|c|c|c|c|c|c|c|}
\hline \multirow[b]{3}{*}{ Nonsmorkers } & \multicolumn{3}{|c|}{ Men } & \multicolumn{3}{|c|}{ Women } \\
\hline & \multicolumn{2}{|c|}{$\mathrm{n}$} & \multirow{2}{*}{$\frac{\text { age }}{38.6 \pm 11.7}$} & \multicolumn{2}{|c|}{$\mathrm{n}$} & age \\
\hline & 118 & (67) & & 31 & (25) & $25.4 \pm 6.9$ \\
\hline PS (-) group & 32 & (28) & $25.2 \pm 7.7$ & 15 & (12) & $25.4 \pm 7.4$ \\
\hline PS (+) group & 86 & (39) & $42.6 \pm 9.6$ & 16 & (13) & $25.1 \pm 6.3$ \\
\hline Smorkers & 125 & $(38)$ & $37.4 \pm 10.2$ & 11 & (3) & $34.0 \pm 12.6$ \\
\hline 1 19/day group & 35 & (9) & $32.4 \pm 9.6$ & 9 & (2) & $33.1 \pm 11.6$ \\
\hline 20 /day group & 90 & (29) & $39.3 \pm 9.8$ & 2 & (1) & $38.0 \pm 13.0$ \\
\hline Total & 243 & (105) & $37.7 \pm 11.1$ & 42 & (28) & $27.5 \pm 9.3$ \\
\hline
\end{tabular}

Data are given in mean \pm S.E. ( ): number of the subjects who were measured for exhaled CO levels. PS: passive smoking. 


\section{Measurement of $\mathrm{CO}$ concentration in the expirium}

The 133 subjects were measured for $\mathrm{CO}$ concentration in their expirium in the afternoon of the same day of urine sampling, using New Micro Smoker Lyzer (Bedfont Company, England). As instructed in the manual of the apparatus, the subjects were asked to inhale a maximum of air, to stop breathing for $15 \mathrm{sec}$., and then to exhale slowly to the completion of expirium.

\section{Time course of $\mathrm{CO}$ in the expirium after smoking}

The smokers were asked to smoke one cigarette (Seven Stars Light, Japan Tobacco Industry) in 10 minutes. They were measured for the $\mathrm{CO}$ concentration in their expirium before smoking, 3, 5, 10 minutes after smoking, and thereafter at an interval of 10 minutes until 90 minutes.

\section{Statistical evaluations}

We computed geometric mean values for MA because the values for this level showed a normal distribution when they had been logarithmically converted. Arithmetic means were computed for $\mathrm{CO}$ levels because they showed normal distribution. The difference of means in three or more groups was evaluated by an analysis of variance and Scheffe's analysis for multiple comparison.

\section{Results}

Time course of excretion of MA in the urine after smoking Fig. 1 shows the changes with time in urinary MA levels

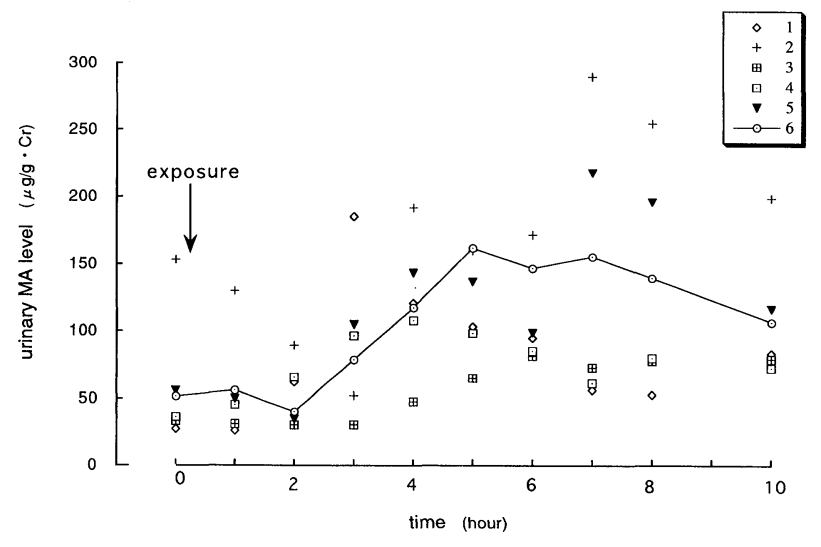

Fig. 1. Time course of urinary MA levels after smoking.

The urinary MA levels in 6 subjects are plotted. Values for the typical subject are connected. The urinary MA level started to rise in $2.8 \pm$ 0.48 hours and reached the peak in $4.8 \pm 0.60$ hours after smoking. The biological half life was $7.5 \pm 0.85$ (5.5-10.7) hours. in 6 smokers after smoking. We calculated the apparent elimination rate $(\mathrm{Ke})$ and the corresponding half life $\left(\mathrm{t}_{1 / 2}\right)$ by the way of Boogaard and Sittert ${ }^{23)}$. The following formula was used:

$$
\begin{aligned}
& \ln \left(C_{2}-C_{1}\right)=-K e \times\left(t_{2}-t_{1}\right), \\
& t_{1 / 2}=-\ln (2) / K e,
\end{aligned}
$$

where $\mathrm{C}_{1}$ denotes the concentration of $\mathrm{MA}$ in the urine sample collected at the peak time $t_{1}$ and $C_{2}$ the concentration of MA at the last sampling time $\mathrm{t}_{2}$. The urinary MA level started to rise in $2.8 \pm 0.84$ hour, and reached the peak in $4.8 \pm 0.60$ hours after smoking. The biological half life was $7.5 \pm 0.85$ (5.5-10.7) hours.

\section{Time course of $\mathrm{CO}$ in the expirium after smoking}

Fig. 2 shows the $\mathrm{CO}$ concentration with time in the expirium of 6 smokers after smoking. We calculated corresponding half life $\left(\mathrm{t}_{1 / 2}\right)$ by the same way of the calculation for urinary MA. The $\mathrm{CO}$ in the expirium started to rise immediately after smoking, and reached the peak in 3 minutes. The biological half life was $3.0 \pm 0.36(1.5-4.1)$ hours.

\section{Evaluation of exposure to tobacco smoke by urinary $M A$ level}

As shown in Fig. 3, the PS (+) group gave a significantly higher mean value than the PS $(-)$ group $(\mathrm{P}<0.01)$. The 20 cigarettes/day or more smoking group gave a significantly higher mean value than the 1-19 cigarettes/day group $(\mathrm{P}<0.001)$. However, there was no significant difference

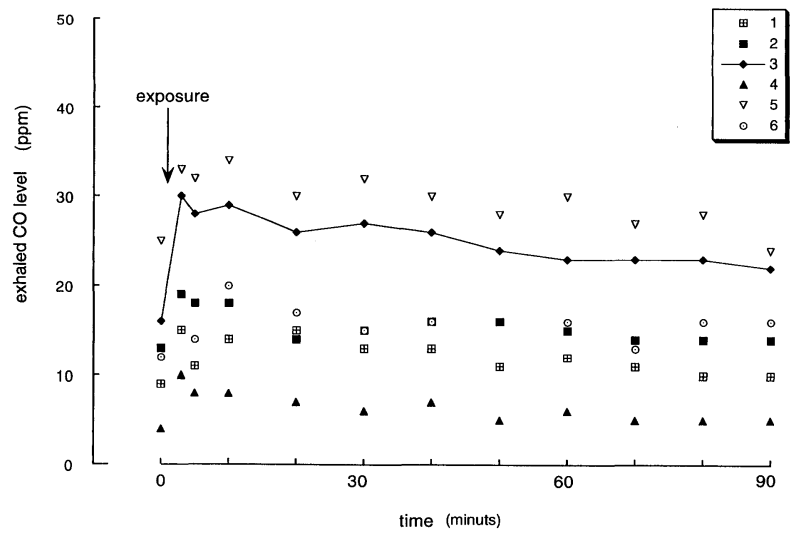

Fig. 2. Time course of $\mathrm{CO}$ concentration in expirium after smoking. The exhaled CO levels in 6 sbjects are plotted. Values for the typical subject are connected. The $\mathrm{CO}$ concentration in the expirium started to rise immediately after smoking and reached the peak in 3 minutes. The biological half life was $3.0 \pm 0.36(1.5-4.1)$ hours. 


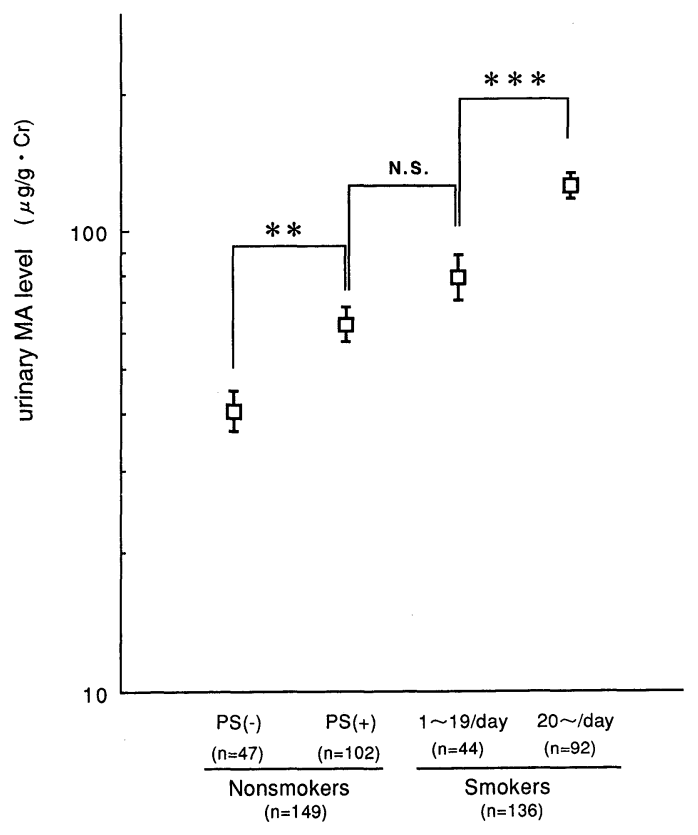

Fig. 3. Geometric mean urinary MA levels by the types of smoking.

SE is expressed in barr. The PS (+) group gave a higher mean value than the PS (-) group. P.S., passive smoking; N.S., not significant; **, $\mathrm{P}<0.01 ; * * *, \mathrm{P}<0.001$.

between the 1-19 cigarettes/day smoking group and the PS $(+)$ group, although the former gave a slightly higher value than the latter.

Fig. 4 shows a comparison among the PS (-) group and two divided PS (+) groups according to the time of sampling, the AM group and the PM group. There was no significant difference between the PS (-) group and the PS (+) AM group. The PS (+) PM group gave a significantly higher value than the PS $(+)$ AM group $(P<0.01)$. All samples of PS (-) were obtained in the afternoon.

Fig. 5 shows the relationship between the urinary MA level and the number of consumed cigarettes per day. A significant and moderate correlation was observed between them $(\mathrm{r}=0.651 ; \mathrm{P}<0.001)$.

\section{Evaluation of exposure to tobacco smoke by exhaled $\mathrm{CO}$ concentration}

As shown in Fig. 6, the PS (+) group and the 1-19 cigarettes/day smoking group gave significantly higher mean values than the PS (-) group and the PS (+) group, respectively $(\mathrm{P}<0.001)$. The 20 cigarettes/day or more smoking group gave a significantly higher value than the $1-19$ cigarettes/day group $(\mathrm{P}<0.05)$.

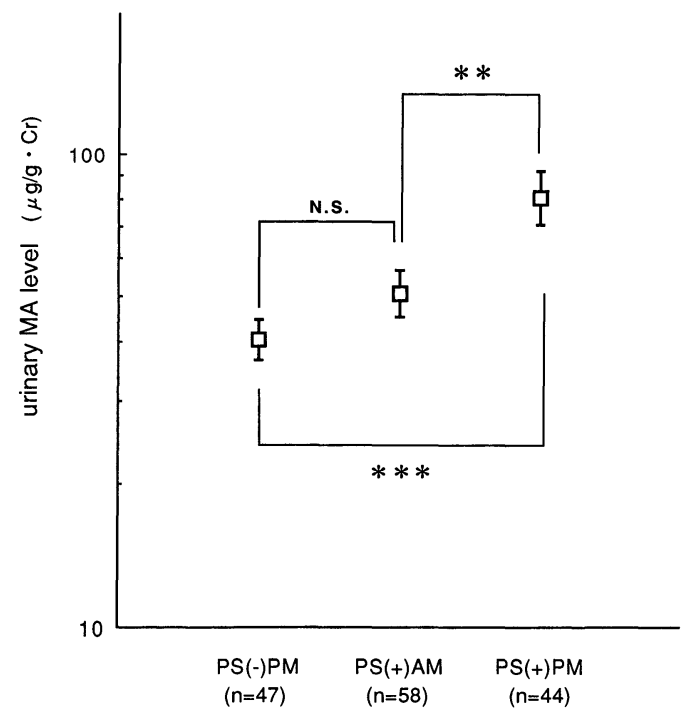

Fig. 4. Geometric mean urinary MA levels for nonsmokers with passive smoking (-) group and the passive smoking (+) groups.

The passive smoking (+) group is divided into two groups according to the sampling time such as AM (morning) and PM (afternoon). SE is expressed in barr. P.S., passive smoking; N.S, not significant; **, $\mathrm{P}<0.01 ; * * *, \mathrm{P}<0.001$.

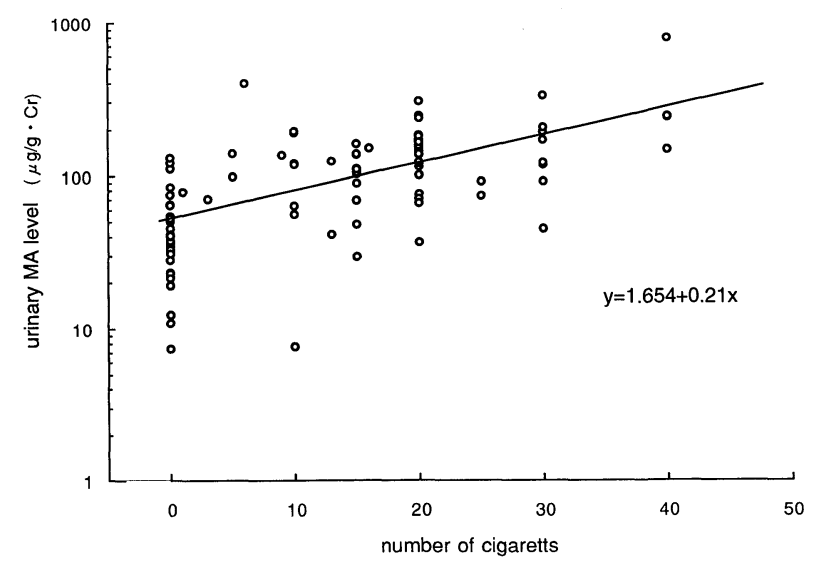

Fig. 5. Correlation of urinary MA level with the number of consumed cigarettes per day.

The logarithmically scaled levels of urinary MA on the vertical axis were plotted against the number of cigarettes per day on the horizontal axis. A moderate and significant correlation was observed between them. $r=0.651 ; n=183 ; P<0.001$.

Fig. 7 shows the relationship between the $\mathrm{CO}$ concentration in the expirium and the number of cigarettes smoked. A highly significant correlation was observed between them $(\mathrm{r}=0.863 ; \mathrm{P}<0.001)$. 


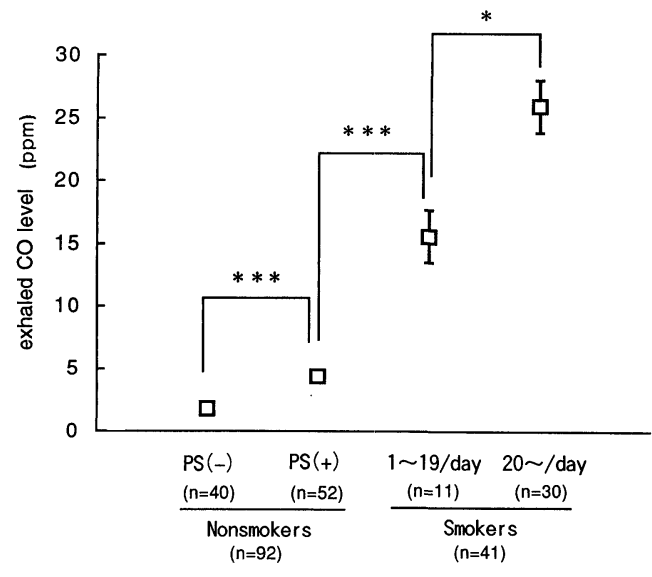

Fig. 6. Arithmetic means of $\mathrm{CO}$ concentration in the expirium by the types of smoking.

$\mathrm{SE}$ is expressed in barr. P.S., passive smoking; *, $\mathrm{P}<0.05$; $* * *, \mathrm{P}<0.001$.

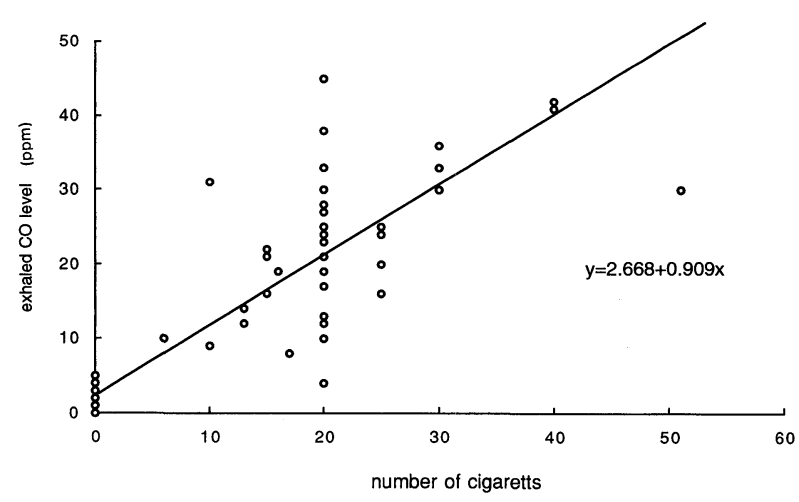

Fig. 7. Correlation of $\mathrm{CO}$ concentration in the expirium with the number of consumed cigarettes per day.

The $\mathrm{CO}$ levels in the expirium on the vertical axis were plotted against the number of cigarettes on the horizontal axis. A highly and significant correlation was observed between them. $\mathrm{r}=0.863 ; \mathrm{n}=81 ; \mathrm{P}<0.001$.

\section{Correlation of exhaled $C O$ concentration with urinary $M A$} level

Fig. 8 show the correlation of exhaled CO level with urinary MA level for PS (-), PS (+), and smoker groups respectively. No significant correlation was observed in all groups.

\section{Discussion}

It has already been pointed out that MA was effective as an index for exposure to benzene in the working environment ${ }^{21-24)}$. Because MA can be used to evaluate the
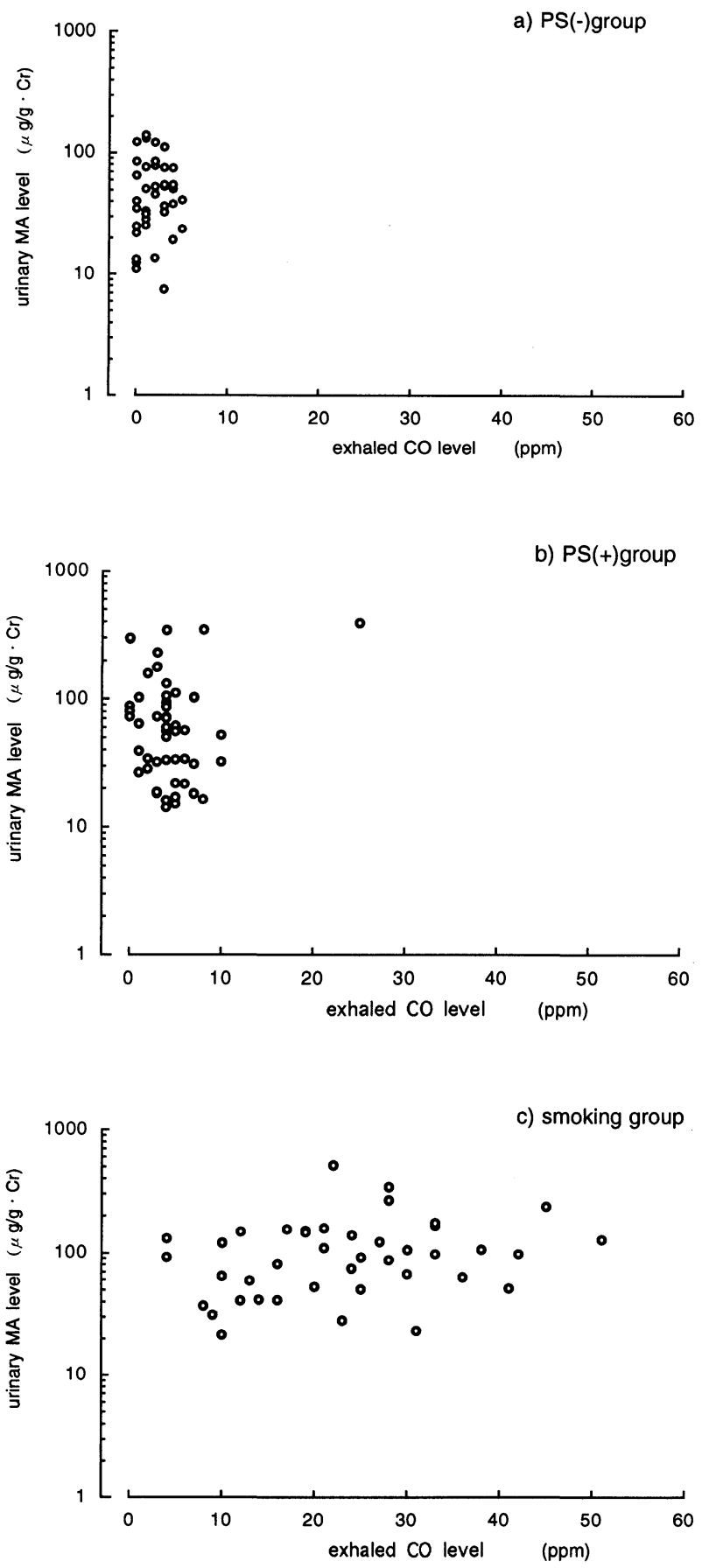

Fig. 8. Correlation of urinary MA level with exhaled CO levels. The logarithmically scaled values for urinary MA levels on the vertical axis were plotted against the exhaled $\mathrm{CO}$ concentration on the horizontal axis. a) In passive smoking (-) group, no significant correlation was observed between them. $r=0.07 ; n=40 ; P=0.669$. b) In passive smoking $(+)$ group, no significant correlation was observed between them. $r=0.057 ; n=52 ; P=0.688$. c) In smokers, mild but no significant correlation was observed between them. $r=0.265 ; n=41$; $\mathrm{P}=0.941$. P.S., passive smoking. 
exposure to trace amounts of benzene, it has been applied

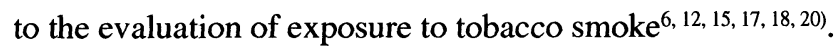

In this study, the urinary MA levels were measured for 285 subjects by a modified method of Ghittori et al. ${ }^{18)}$. A moderate and significant correlation was observed between the number of cigarettes smoked and the urinary MA levels. When the urinary MA levels for the PS (+) group were divided into two groups according to the time of sampling, the PM group gave a significantly higher mean urinary MA level than did the AM group. This suggests that nonsmokers inhale tobacco smoke in non-partitioned workplaces and the effects of PS are more remarkable when the urine samples are obtained in the afternoon than in the morning.

No significant difference of mean urinary MA levels was observed between the PS (+) group and the 1-19 cigarettes/ day smoking group. It can be predicted that nonsmokers working in non-partitioned workplaces and light smokers are exposed to similar amount of tobacco smoke.

We studied the time course of excretion of urinary MA after smoking and found that the half life of MA was about $7.5 \pm 0.85$ hours. The results suggest that smokers have low urinary MA levels in the morning, because inhaled benzene in the tobacco smoke was metabolized and excreted into urine during night. This seems to be proved by a significant difference between the PS (+) AM group and the corresponding PM group. If nonsmokers have been exposed to tobacco smoke before work shift in their home, the effects of passive smoking persist in the morning. The MA level in the urine sample obtained in the morning does not indicate the tobacco exposure at the workplace.

In the measurements of $\mathrm{CO}$ concentration in the expirium, a significant difference was observed between the PS (-) and the PS (+) group. A significant difference was also observed even between the 1-19 cigarettes/day group and the PS (+) group. These results were different from the results of the measurement of urinary MA levels.

The correlation is very high between the exhaled $\mathrm{CO}$ concentration and the number of consumed cigarettes. Because $\mathrm{CO}$ has a peak in 3 minutes after smoking and the biological half life is as short as $3.0 \pm 0.36(1.5-4.1)$ hour, the exhaled $\mathrm{CO}$ levels in nonsmokers are greatly affected when exposed to environmental tobacco smoke just before the measurement. Therefore, the $\mathrm{CO}$ concentration in the expirium is a good index only for smokers who are frequently and periodically exposed to tobacco smoke, but is not a suitable index for evaluating passive smokers who irregularly inhale environment tobacco smoke ${ }^{6}$. Therefore, significant correlation was not observed between the MA level in urine and $\mathrm{CO}$ levels in the expirium.

Urinary cotinine is the main metabolite of nicotine, the principal alkaloid of the tobacco plant. The urinary cotinine has been measured to evaluate the effects of passive smoking6, 16). The nicotine yield of cigarette main stream smoke (MS) is about $1 \mathrm{mg} /$ cigarette, and the side stream smoke (SS)/MS ratio amounts to 2.6-3.3. Urinary cotinine has a biological half life of as long as $16-20$ hours $^{6,16)}$. The urinary cotinine level is affected with passive smoking at places other than workplace, because of it's long half life ${ }^{6,8)}$.

MA is one of the metabolite of benzene. Benzene was emitted 30-50 $\mu \mathrm{g} /$ cigarette in MS and 345-653 $\mu \mathrm{g} /$ cigarette in $\mathrm{SS}^{6}$. The SS/MS ratio of benzene is more than 10 times that of nicotine. MA excretion reaches the peak in $4.8 \pm$ 0.60 hours after smoking, and MA has the biological half life of $7.5 \pm 0.85$ hours. It is possible to exclude the effects of passive smoking at home to some extent by taking urine samples at the end of work shift in the afternoon.

Urinary MA is also detected following dietary intake of food preservative sorbic acid. Estimated daily intake of sorbic acid was $29.0 \mathrm{mg}$ per day based on the results of the "National Nutrition Survey" published by the Ministry of Health and Welfare, Japan ${ }^{25)}$. Under the experimental conditions the estimated conversion of sorbic acid to urinary MA was $0.12 \%$ $(0.08-0.19 \%)^{20)}$. Thus, urinary excretion of MA due to dietary sorbic acid is calculated to be $2.48 \mu \mathrm{g} / \mathrm{g} \cdot$ creatinine. This is small enough to disregard the effect of ingested sorbic acid.

To evaluate the passive exposure to tobacco smoke at workplaces, the method should be sensitive enough, easy to test, and as inexpensive as possible. In evaluating the passive exposure to tobacco smoke, we consider that the measurement of urinary MA level is superior to the measurement of urinary cotinine level, because the SS/MS ratio of benzene was reported higher than nicotine, and urine samples taken once in the afternoon are sufficient to evaluate the exposure to tobacco smoke at workplaces.

\section{Acknowledgments}

The authors thank Ms. Yumiko Sugiura for her technical assistance.

\section{References}

1) Asano M (1985) Environments and health effects of passive smoking. Kokyu 4, 478-91 (in Japanese).

2) Chow JY, Ma L, Cho CH (1996) An experimental model for studying passive cigarette smoking effects on gastric 
ulceration. Life Sci 58, 2415-22.

3) Nilsson R (1996) Environmental tobacco smoke and lung cancer: A reappraisal. Ecotoxicol Environ Saf 34, 2-17.

4) Dockery DW, Trichopoulos D (1997) Risk of lung cancer from environmental exposures to tobacco smoke. Cancer Causes Control 8, 333-45.

5) Hausberg M, Mark AL, Winniford MD, Brown RE, Somers VK (1997) Sympathetic and vascular effects of short-term passive smoke exposure in healthy nonsmokers. Circulation 96, 281-7.

6) Scherer G, Richter E (1997) Biomonitoring exposure to environmental tobacco smoke (ETS): a critical reappraisal. Hum Exp Toxicol 16, 449-59.

7) Yang CY, Chiu JF, Cheng MF, Lin MC (1997) Effects of indoor environmental factors on respiratory health of children in a subtropical climate. Environ Re 75, 49-55.

8) Repace JL, Jinot J, Bayard S, Emmons K, Hammond SK (1998) Air nicotine and saliva cotinine as indicators of workplace passive smoking exposure and risk. Risk Anal 18, 71-83.

9) Nicholas JW, Marianne I, Jillian B, Alan B (1981) Carbon monoxide in breath in relation to smoking and carboxyhemoglobin levels. Thorax 36, 366-9.

10) Martin JJ, Hugh TP, Colin F, Cyril V, Yussuf S (1987) Comparison of tests used to distinguish smokers from nonsmokers. Am J Public Health 77, 1435-8.

11) Nogami H, Kanou E, Takayama K, Iwamoto $S$, Hashimoto M (1991) Assay for nicotine metabolites in passive smokers' urine by high- performance liquid chromatographic method. Osakafuritsu Koueiken Hou 12 (in Japanese).

12) Lee BL, New AL, Kok PW, Ong HY, Shi CY, Ong CN (1993) Urinary trans, trans-muconic acid determined by liquid chromatography: Application in biological monitoring of benzene exposure. Clin Chem 39, 178892.

13) Miwa K, Miyagi Y, Asanoi H, Fujita M, Sasayama $S$ (1993) Augmentation of smoking cessation education by urinary cotinine measurement. Jpn Circ J 57, 77580.

14) Kurose $M$, Nishioka $K$, Ootani $K$, Morita $M$, Nishioka $\mathrm{T}$, Yasumatsu H (1994) Application of arterial carboxyhemoglobin analysis by $\mathrm{CO}$-oximeter to diagnosis of current smokers. Igakukensa 43, 1879 82 (in Japanese).

15) Ong CN, Lee BL, Shi CY, Ong HY, Lee HP (1994) Elevated levels of benzene-related compounds in the urine of cigarette smokers. Int J Cancer 59, 177-80.

16) Willers S, Skarping G, Dalene M, Skerfving S (1995) Urinary cotinine in children and adults during and after semiexperimental exposure to environmental tobacco smoke. Arch Environ Health 50, 130-38.

17) Buratti M, Fustinoni S, Colombi A (1996) Fast liquid chromatographic determination of urinary trans, transmuconic acid. J Chromatogr B 667, 257-63.

18) Ghittori S, Maestri L, Rolandi L, Lodola L, Fiorentino ML, Imbriani M (1996) The determination of trans, trans-muconic acid in urine as an indicator or occupational exposure to benzene. Occup Enviro Hyg 11, 187-91.

19) Coutrim MX, Jager AV, de Carvalho LR, Tavares MF (1997) Capillary electrophoresis determination of urinariy muconic acid as a biological marker for benzene in cigarette smoke. J Capillary Electrophor 4, 39-45.

20) Ruppert T, Scherer G, Tricker AR, Adlkofer F (1997) Trans, trans-muconic acid as a biomarker of nonoccupational environmental exposure to benzene. Int Arch Occup Environ Health 69, 247-51.

21) Inoue $O$, Seiji $K$, Nakatsuka $H$, Watanabe $T$, Yin $S N$, Li GL, Cai SX, Jin C, Ikeda M (1989) Urinary t,tmuconic acid as an indicator of exposure to benzene. Br J Ind Med 46, 122-7.

22) Ohnson ES, Lucier G (1992) Perspective on risk assessment impact of recent reports on benzene. Am J Ind Med 52, 611-20.

23) Boogaard PJ, van Sittert NJ (1995) Biological monitoring of exposure to benzene: A comparison between s-phenylmercapturic acid, trans, trans-muconic acid, and phenol. Occup Environ Med 52, 611-20.

24) Ong CN, Kok PW, Ong HY, Shi CY, Lee BL, Phoon WH, Tan KT (1996) Biomarkers of exposure to low concentrations of benzene: A field assessment. Occup Environ Med 53, 328-33.

25) Ishiwata $H$, Nishijima $M$, Fukasawa $Y$, Ito $Y$, Yamada $\mathrm{T}$ (1996) Evaluation of sorbic acid contents in foods and the daily intake deduced from the results of official inspection in Japan in F. Y. 1994. Shokueishi 37, 37884 (in Japanese). 